\title{
From curriculum design to enactment in technology enhanced mathematics instruction - Mind the gap!
}

\author{
Alison Clark-Wilson and Celia Hoyles \\ UCL Institute of Education, University College London \\ a.clark-wilson@ucl.ac.uk
}

\begin{abstract}
A 3-year study of 209 mathematics teachers in England implementing Cornerstone Maths curriculum units for lower secondary mathematics that embed dynamic technology provides a rich data set on teachers' curriculum enactments. Focusing on the curriculum unit on linear functions, we report gaps between teachers' planned and actual curriculum enactments, which are to be expected. By focusing on the 'at scale' and individual teacher outcomes, the research reveals new insights into the complexities of technology integration in mathematics instruction. For example, the case of Amy serves to highlight how a teacher's intended enactment is challenging in reality, whilst providing worthwhile classroom experience that supported the emergence of professional knowledge for teaching mathematics with technology.
\end{abstract}

\section{Keywords}

mathematics education, technology-enhanced mathematics instruction, Cornerstone Maths, linear functions, mathematical pedagogical technology knowledge (MPTK); hiccups; landmark activity

\section{Introduction}

This paper addresses an aspect of curriculum ergonomics, teachers' enactments of curriculum materials, that are manifested in two ways. The first, their written plans for classroom activities (intended enactment) and the second, their classroom activity that results (real enactment). The notion of the intended and real curriculum was first proposed by Stenhouse, who summarised the "curriculum problem" thus, "the curriculum in the mind [of the teacher] or on paper, to the curriculum in the classroom" (Stenhouse, 1975, p. 105). An underlying assumption is the consistent research finding that there is "not a direct relationship between the design of curriculum materials and the resulting instructional experiences" (Choppin, 2011, p. 333). Prior research has identified the need to narrow this gap through the design of materials that allow for 
teacher adaptation, whilst providing sufficient content such that the underpinning design principles of the intervention are retained (Hoyles, Noss, Vahey, \& Roschelle, 2013).

In the study reported here, the teachers were engaged in a research project that aimed to articulate how their mathematical pedagogical technology knowledge (MPTK, Thomas \& Palmer, 2014) developed as they learned to use Cornerstone Maths (CM) dynamic mathematical technology (DMT) for the teaching of linear functions in the lower secondary school phase (11-14 years in England). The results of this study have been extensively reported (Clark-Wilson \& Hoyles, 2017a, 2017b, In press). Here, we investigate how specific teachers' planned enactments played out in the reality of their classrooms, providing insights into what and how they learned through this process, and give indications as to how the gap might be narrowed.

\section{Theoretical framework}

\section{Enactments of the Cornerstone Maths curriculum}

As highlighted by Stenhouse, the notion of curriculum is multi-faceted and culturally located. In England, where the study took place, the mathematics National Curriculum prescribes the curriculum vision and lists the mathematical content to be taught but does not offer any specific pedagogical approaches in the form of resource recommendations, such as the use of dynamic mathematical technologies (DMT). Consequently, the National Curriculum is often realised at the school level through the localised 'scheme of work' that sequence the teaching and assessment activities. Schools purchase curriculum materials from publishers (text books or digital schemes), access open educational resources (OERs, such as Cornerstone Maths) and/or devise their own teaching materials.

Figure 1 outlines the four phases of curriculum (re)design that concern this study. 


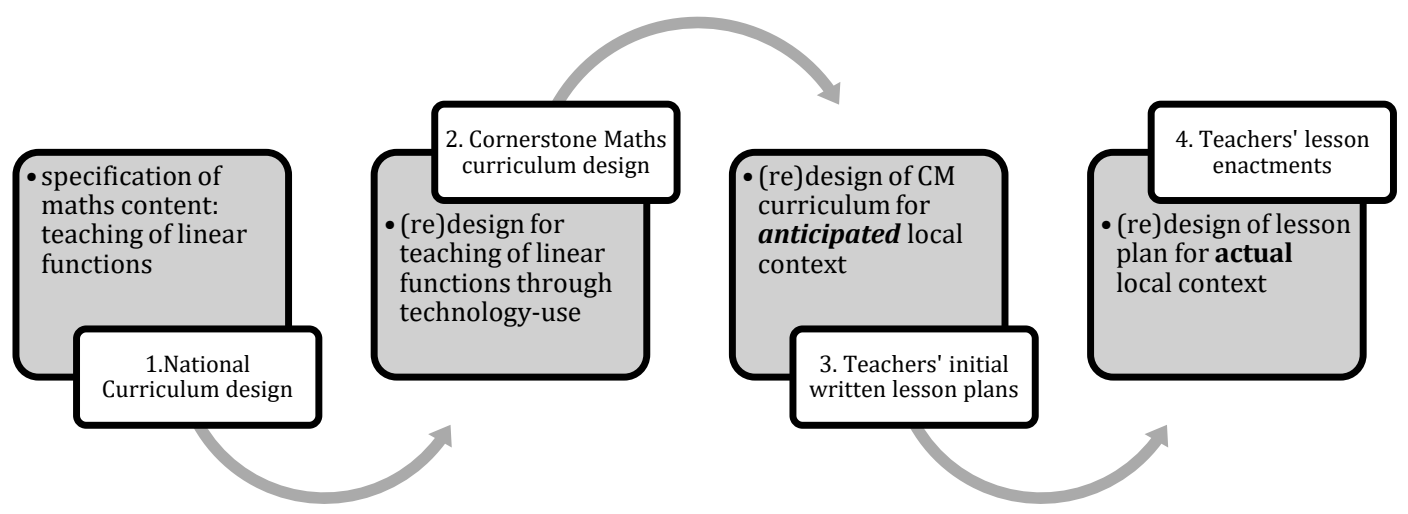

Figure 1 The process and phases of re-design from the National Curriculum to teachers' classroom enactments

Phase 1 is considered a given, with the National Curriculum stating the content for the teaching of linear functions (Department of Education, 2013). Phase 2 took place within a collaborative UK-US project (2011-14) that began with the (re)design (by the UCL Knowledge Lab team in collaboration with teachers as co-designers) of CM from materials developed in the US and subsequently piloted with 429 students from the 9 English 'design' schools. This study established the efficacy of CM and its mandatory professional development (PD) programme of support (Hoyles et al., 2013). The CM curriculum incorporates web-hosted mathematical software, student workbooks and teacher guides, and an accompanying professional development programme. Phases 3 and 4 were situated within a follow-on project based in London secondary schools during 2015-17, funded by Nuffield Foundation.

Teaching with dynamic technology in mathematics

In England, DMT is underused (Bretscher, 2014; Office for Standards in Education, 2012) despite over 30 years of research that has consistently highlighted its positive impact on students' understandings of key mathematical ideas (Churchhouse et al., 1986; Hoyles \& Lagrange, 2009; Kaput, 1992). Consequently, in England there have been no prior systematic studies on CM, nor any other digital mathematics curriculum, focused on the third and fourth phases of Figure 1, a gap that this study aims to fill. Furthermore, research findings have consistently highlighted the particular challenges that teachers of mathematics face as they (and their students) begin to use technology 
in the classroom (Clark-Wilson, Robutti, \& Sinclair, 2014; Hoyles \& Lagrange, 2009) ${ }^{1}$. For mathematics, technology affords new: mathematical representations (e.g. dynamically linked functions, graphs and data tables); actions (e.g. dragging sliders that change mathematical variables) and pedagogies (e.g. aggregating students' on-screen findings, sharing student productions). Consequently, it is unsurprising that the introduction of mathematical technologies ${ }^{2}$ can prompt for the teacher a, possibly unwelcomed (depending on the teacher's goals, philosophy etc.) rethinking of their mathematical knowledge, which encompasses the associated pedagogy (Artigue, 1998). A number of studies have shed light on the processes through which teachers develop such knowledge and highlighted the important role for 'hiccups' or 'critical incidents' within actual classroom practice as a context for teachers' situated learning (Aldon, 2011; Clark-Wilson, 2010).

The CM curriculum on linear functions and its 'landmark activity'.

Landmark activities originate from Winograd and Flores' concept of cognitive breakdown, or 'situation[s] of non-obviousness' $(1986,165)$, in which established routines are replaced by conflict, disagreement or doubt (Hoyles, Noss and Kent, 2010). Thus, we define landmark activities as those that can provoke a rethinking of the mathematics or an extension of previously held ideas - the 'aha!' moments that show surprise - and provide evidence of students' developing appreciation of the underlying concept (Clark-Wilson, Hoyles and Noss, 2015).

Given that the CM linear functions curriculum unit included at least eight hours of lesson materials and the CM PD design required teachers to engage in a highly focused lesson planning task (described in Clark-Wilson \& Hoyles, 2017a), the research team chose one landmark activity which, guided by the following selection criteria, should:

- introduce and consolidate a significant aspect of mathematical knowledge, a 'big mathematical idea', through a realistic context;

- include design features of the DMT that offer new dynamic ways to engage with the mathematics (the design principles); and

\footnotetext{
1 These challenges mainly concern teachers as they have mostly learnt mathematics in non-digital environments

2 We distinguish mathematical technologies from generic technologies such as interactive whiteboards or tablets.
} 
- be selected from mid-way through the curriculum unit, so that teachers and students would have some prior experience of the mathematics, technology and context.

So, for the linear functions curriculum unit, the activity "Shakey the Robot" was selected as it introduced the big mathematical ideas outlined in Figure 2 and, most significantly, algebraic notation $(y=m x+c)$ to describe constant velocity motion.

Context: Let's work on a game with robots.

We need to set up the mathematics to make our robots move at different speeds.

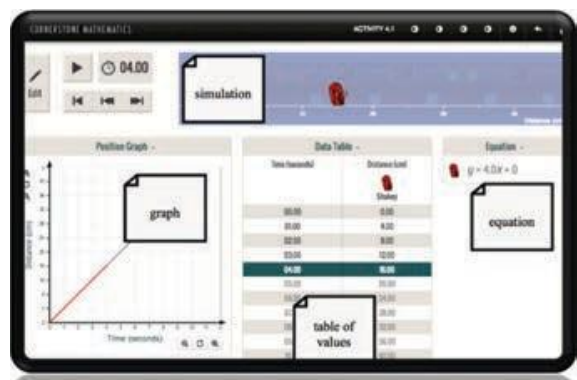

\section{Big mathematical ideas:}

- Coordinating algebraic, graphical, and tabular representations.

- Speed as a context to introduce rates of change.

- $y=m x+c$ as a model of constant velocity motion - the meaning of $m$ and $\mathrm{c}$ in the motion context.

\section{DMT design principles:}

- dynamic simulation and linking between representations.

- drive the simulation from the graph (through draggable 'hotspots') or the function (by editing values).

- show/hide representations, as appropriate.

Figure 2 Overview of the linear functions landmark activity, 'Shakey the robot'.

Teachers' mathematical pedagogical technology knowledge.

The overarching theoretical frame for the study is Thomas et al's Mathematical Pedagogical Technology Knowledge (Thomas \& Hong, 2013; Thomas \& Palmer, 2014), as shown in Figure 3. 


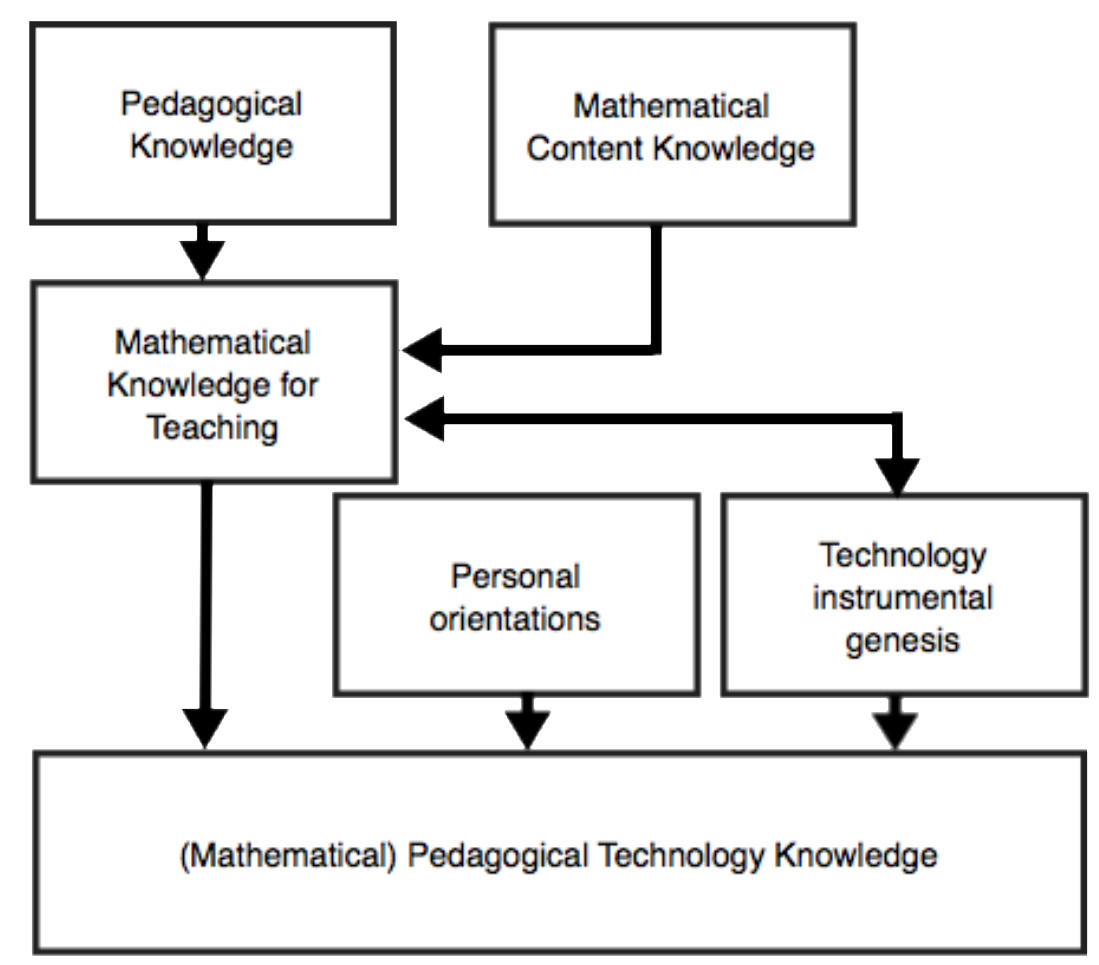

Figure 3. Components of Mathematical Pedagogical Technology Knowledge (Thomas \& Hong 2013, Thomas \& Palmer 2014).

MPTK is a mathematics-specific frame that positions knowledge as a holistic set of relations between:

- mathematical content knowledge;

- pedagogical knowledge (Shulman, 1987);

- mathematical knowledge for teaching (Ball, Hill, \& Bass, 2005);

- personal orientations (goals, attitudes, dispositions, beliefs, values, tastes and preferences) (Schoenfeld, 2011);

- technology instrumental genesis: The crucial process through which the teachers' mathematical knowledge shapes - and is shaped by - their interactions with the technology as they accomplish a particular mathematical task (Guin \& Trouche, 1999). For example, by dragging a movable point on the graph of a function, new insights into the properties of functions might be gained. ${ }^{3}$

\footnotetext{
${ }^{3}$ Whilst the MPTK framework considers teachers' technology instrumental geneses, it is important to note also that the students also develop such knowledge through their interactions with the DMT. Hence, it is an important component of a teacher's MPTK to consider students' instrumental genesis in their lesson plans and subsequent enactments.
} 
This frame is operationalised by offering lenses through which to view teachers' emerging knowledge as seen through their classroom enactments, both intended and real.

\section{Methods}

The project involved 209 teachers from 48 London secondary schools in the period Jan 2014 - July 2016. Teachers were either self-selecting or nominated by their school and they or their schools chose for them to be involved in up to three cycles of professional development that enabled them to plan, teach and evaluate a landmark activity from each of the three Cornerstone Maths curriculum units. Some schools opted to send the same teacher(s) to two or three of these cycles. This paper adopts a macro-view of 60 teachers alongside a micro-view of one of these teachers, Amy, who all participated in the mandatory 1.5 day PD programme for the CM linear functions curriculum unit over an eight week time period. The programme involved the cyclical activities described in Figure 4, an adaptation of Japanese lesson study, an approach that was informed by the work of Foster, Swan \& Wake in English secondary mathematics departments (2014).

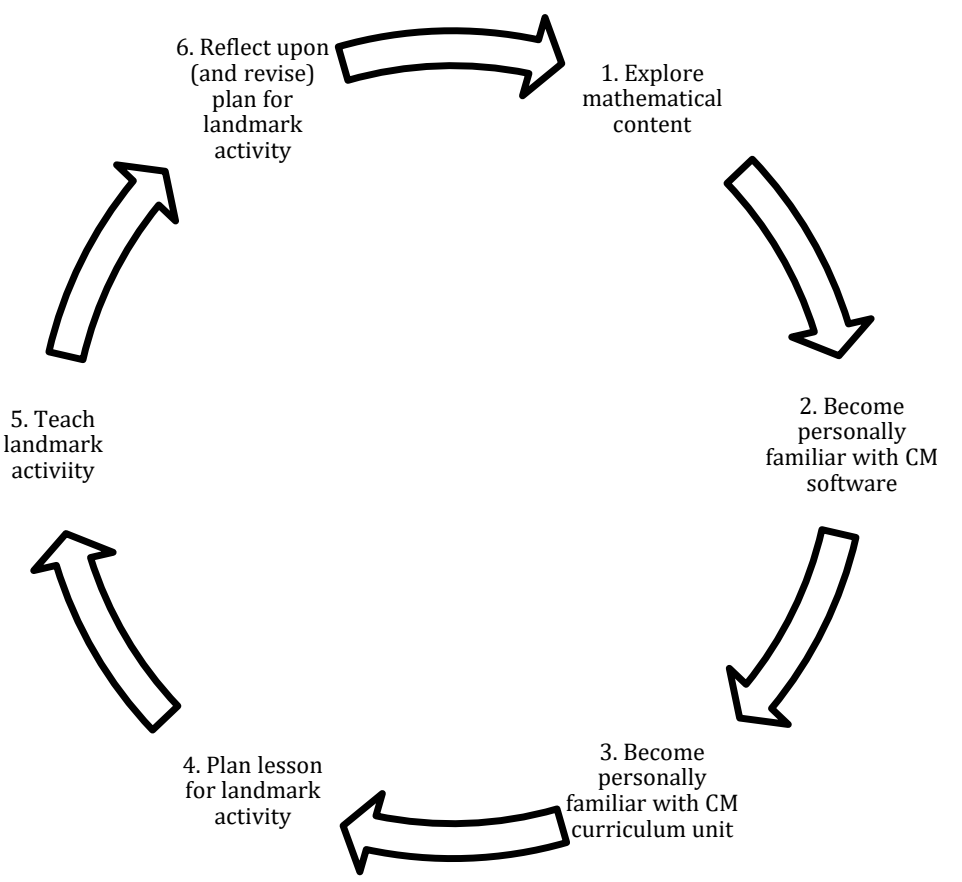

Figure 4. PD cycle for the CM linear functions curriculum unit

The lesson planning task was initially carried out as a collaborative task between pairs or trios of teachers from the same school using a common planning proforma (Appendix A) that captured the following information:

- contextual information about the class (i.e. age, ability level); 
- teacher's preparation notes;

- students' prior experience/skills with the software;

- key intended learning outcomes for the students;

- description of the planned phases of the lesson that included the teacher's intended actions and the anticipated students' responses to these.

The 60 teachers produced 42 plans in total (as some were jointly produced).

Furthermore, all teachers created and shared their lesson plans in real-time within the project online community, which was visible to all participants during the initial synchronous planning task. The teachers were actively encouraged to review each other's plans and to adopt or adapt the text, as they thought useful. The teachers were encouraged to produce the best plan possible, although it was understood that, as they taught the CM curriculum tasks that preceded the identified landmark activity, they would need to review and revise their plan in the light of this classroom experience. A sample of 12 teachers was selected for follow-up classroom observations of their teaching of the landmark activity to reflect the range of reported experience and confidence with DMT, subject to the mutual availability of individual teachers and researchers. The non-participant observations of the teaching were audio- and videorecorded and the teacher's actions throughout the approximately one-hour ${ }^{4}$ lesson were noted using a visual mind mapping tool that detailed the multiple phases of the landmark activity during the lesson (see Appendix B). These maps, which should be read clockwise, recorded the phases of the teachers' words and actions that instigated the students' work (subsequently enhanced by accurate audio-transcriptions). This methodology enabled a qualitative comparison to be made between the teacher's enactment of the lesson alongside the teacher's espoused written plan. Audio-recorded pre- and post-discussions with the 12 teachers were also conducted.

\section{Analysing the lesson plans}

The 42 lesson plans for the landmark activity produced during the PD sessions were analyzed using an open coding constant comparison method, which led to a set of eight hypothesised features that indicated strong adherence to the original vision and design

\footnotetext{
${ }^{4}$ Lesson duration is determined by individual schools, which varied between $50-70$ minutes in the observed lessons.
} 
principles of a curriculum embedding DMT. The features and their descriptors were validated and further refined in the light of lesson observations and discussions with teachers ${ }^{5}$ leading to the list in Table 1 , with exemplifications from multiple plans:

\begin{tabular}{|c|c|}
\hline Feature of lesson plan & Exemplification \\
\hline $\begin{array}{l}\text { Feature 1. Explicit descriptions of } \\
\text { teachers' actions/ questions }\end{array}$ & $\begin{array}{l}\text { "Draw their attention to the screen - } \\
\text { [Ask] is there anything different from the } \\
\text { previous day?" }\end{array}$ \\
\hline $\begin{array}{l}\text { Feature 2. Explicit descriptions of } \\
\text { students' actions on DMT during the } \\
\text { lesson }\end{array}$ & $\begin{array}{l}\text { "Come back together and project chosen } \\
\text { students' screens onto the main screen } \\
\text { and discuss answers" }\end{array}$ \\
\hline $\begin{array}{l}\text { Feature 3. Appreciation of students' } \\
\text { instrumental knowledge }{ }^{6} \text { (i.e. prior skills } \\
\text { with software, progression of skills in } \\
\text { lesson) }\end{array}$ & $\begin{array}{l}\text { "[Ask] How do we make Shakey go } \\
\text { slowly? reminding them of the use of } \\
\text { control buttons in controlling the time } \\
\text { taken in the simulations" }\end{array}$ \\
\hline $\begin{array}{l}\text { Feature 4. Explicit reference to meaning } \\
\text { of functions (relating to other } \\
\text { representations) }\end{array}$ & $\begin{array}{l}\text { "Students highlight hops on their graph } \\
\text { and table, which is the same as the } \\
\text { gradient }{ }^{7} \text { in their equation" }\end{array}$ \\
\hline $\begin{array}{l}\text { Feature 5. Explicit reference to acting on } \\
\text { representations to change speed }\end{array}$ & $\begin{array}{l}\text { "let the students explore changing the } \\
\text { steepness of the line and whether this } \\
\text { means slower or faster" }\end{array}$ \\
\hline $\begin{array}{l}\text { Feature 6. Explicit use of mathematical } \\
\text { vocabulary }\end{array}$ & $\begin{array}{l}\text { "discuss where time, distance and speed } \\
\text { are on the graph, table and equation" }\end{array}$ \\
\hline $\begin{array}{l}\text { Feature 7. Explicit use of } \\
\text { technological/contextual vocabulary }\end{array}$ & $\begin{array}{l}\text { "Students hit the edit button and } \\
\text { experiment with moving the graph (Ask } \\
\text { how to make it steeper/ less steep etc.) } \\
\text { what hotspots do you need to select?" }\end{array}$ \\
\hline
\end{tabular}

\footnotetext{
${ }^{5}$ As the linear functions curriculum unit was the second topic of three within the CM project, these quality features were initially hypothesised from the data analysis of the previous set of lesson plans that focused on algebraic patterns and expressions.

${ }^{6}$ See Footnote 3 for more detailed explanation.

7 The English curriculum adopts the word 'gradient' to mean the 'slope' or 'steepness' of a line. Also, $y=m x+c$ is the standard notation for $y=a x+b$, which is the more common format in the US.
} 
Feature 8. Includes planned plenary

phases that involved teacher use of software
"Play Shakey simulation; ask students:

How fast is Shakey going?"

Table 1 The eight quality features of lesson plans involving the use of DMT.

The eight features were used to score the quality of the teachers' plans, with one mark being allocated for the presence of the feature within the plan. Multiple occurrences of any feature within one lesson plan were not noted. Consequently, each plan was given a score of between zero and eight.

The relationship between a teacher's intended and real enactments concerning technologyenhanced mathematics instruction and their professional knowledge and practice is highly complex. However, a mapping of the eight quality features of lesson plans does reveal important links between the components of a teacher's MPTK, as shown in Figure 5.

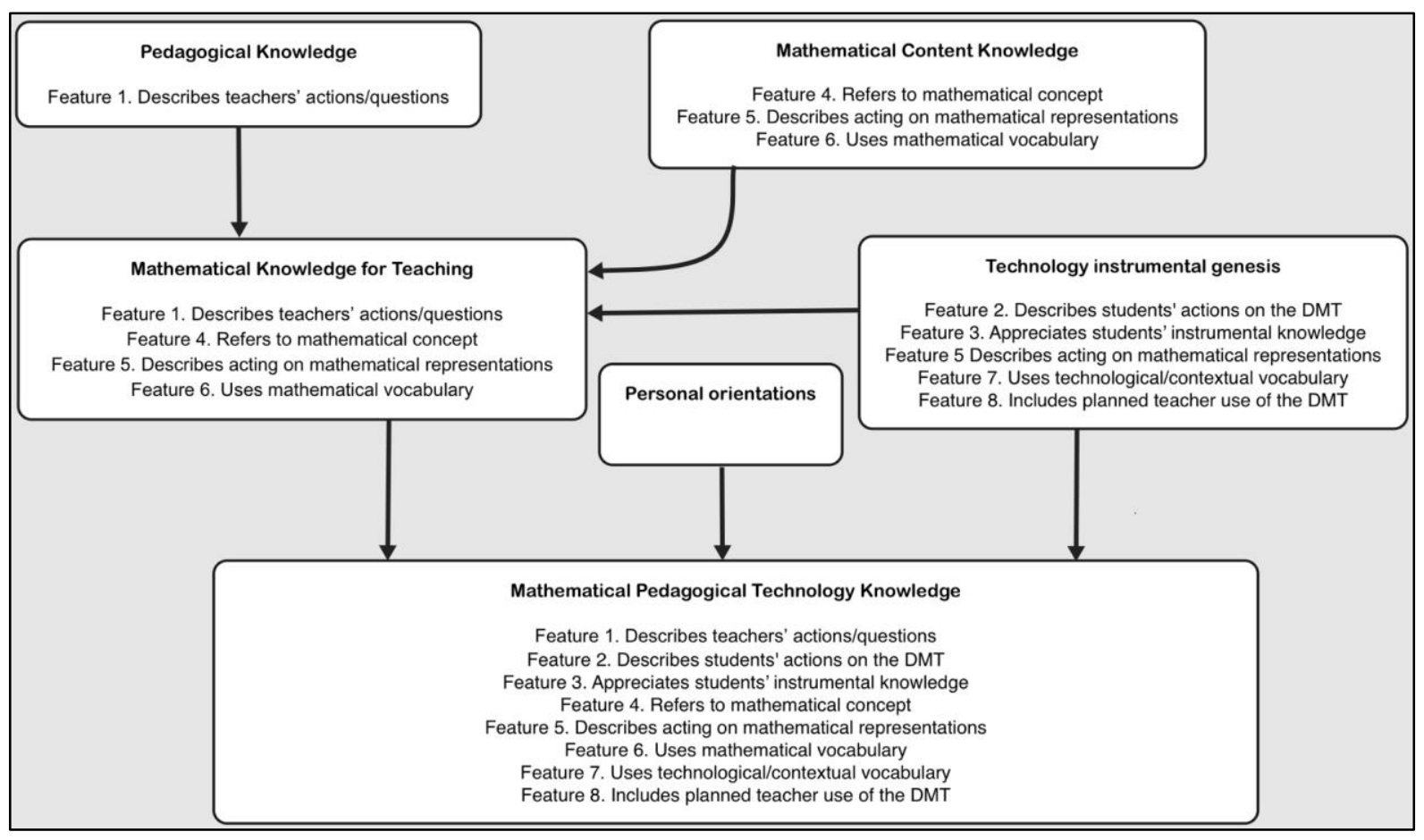

Figure 5 Features of CM landmark activity lesson plans and their relationship to a teacher's MPTK.

Notably, there are no quality features that directly linked to Personal orientations, the aspect of teachers' MPTK that captures their dispositions towards the use of DMT within mathematics teaching and learning. Whilst the existence of a plan provides some indication of this disposition, the pre- and post-lesson interviews with teachers 
provided the more insightful data source, highlighting the importance of the in-depth individual teacher case studies, such as that of Amy, which features later.

\section{Findings}

\section{Intended enactments}

Descriptive results from the analysis of the 42 initial lesson plans for the linear functions landmark activity are shown in Table 2.

\begin{tabular}{|l|c|}
\hline Feature of lesson plan & $\begin{array}{c}\text { Occurrence in plan \% } \\
\text { (n = 42 plans) }\end{array}$ \\
\hline 1. Explicit descriptions of teachers' actions/ questions & $69 \%$ \\
\hline $\begin{array}{l}\text { 2. Explicit descriptions of students' actions on DMT during the } \\
\text { lesson }\end{array}$ & $45 \%$ \\
\hline $\begin{array}{l}\text { 3. Appreciation of students' instrumental knowledge } \\
\text { 4. Explicit reference to meaning of functions (relating to other } \\
\text { representations) }\end{array}$ & $57 \%$ \\
\hline $\begin{array}{l}\text { 5. Explicit reference to acting on representations to change } \\
\text { speed }\end{array}$ & $26 \%$ \\
\hline 6. Explicit use of mathematical vocabulary & $62 \%$ \\
\hline $\begin{array}{l}\text { 7. Explicit use of technological/contextual vocabulary } \\
\text { 8. Planned plenary phases that involved teacher use of } \\
\text { software }\end{array}$ & $31 \%$ \\
\hline
\end{tabular}

Table 2 Analysis of the 42 initial lesson plans in relation to the eight features.

Although lesson planning is an integral and expected aspect of English teachers' professional practice, observations during the PD revealed that teachers were more accustomed to produce a lesson plan that described their students' activity during the lesson rather than a plan for their own words and actions. However, an established and consistent research finding is that it is necessary for teachers to have carefully planned how they will mediate the mathematical ideas through their own use of the technology (Ruthven, 2014). The lack of teachers' initial awareness of this need is revealed by the lower occurrences of Features 2 (45\%), 3 (38\%), 5 (26\%), 7 (31\%) and 8 (24\%), which all relate strongly to the teacher's use of the DMT. Figure 6 corroborates this finding by showing the distribution of quality scores across the 42 initial lesson plans. 


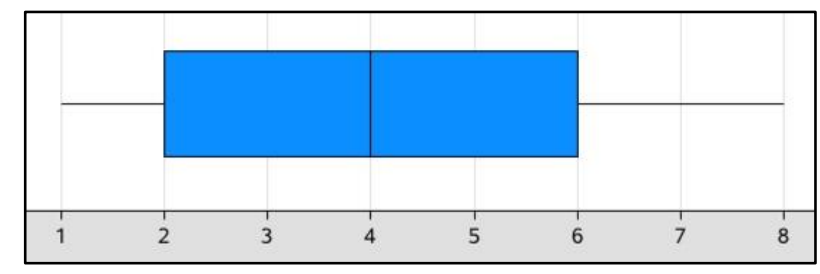

Figure 6. Linear functions: Distribution of quality scores for teachers' initial lesson plans $(n=42, \bar{x}=4.2$

$S D=2.1)$

\section{Real enactments}

The lesson observations revealed that, unsurprisingly, teachers intended enactments were not generally realised in the classroom. Only three of the teachers actually interacted with the CM DMT for themselves during whole-class teaching, although five had indicated in their plan that they intended to do so. Most chose to just display the CM software and gesture at its representations or embed static screen shots of the CM DMT within their lesson presentation slides without ever playing the animation or editing Shakey's motion.

To try to understand this gap between lesson planning and lesson enactment ( $\mathrm{a}$ significant one with respect to technology integration in mathematics education) from the teacher perspective, we now focus on one teacher's real enactment and show how this links to both the MPTK framework and related quality features of her lesson plan. Amy held a Bachelor degree in mathematics and had undergone a one-year, postgraduate university-based teacher preparation programme, indicating her high initial level of mathematical content knowledge. She was in her second year of teaching and had never previously used DMT with any students, although she had encountered the Cornerstone Maths curriculum units during a one-hour workshop session towards the end of her postgraduate course, suggesting she was early in her technology instrumental genesis [knowledge]. During the project, Amy had collaborated with a supportive, more experienced senior colleague and, together, they produced one of the highest quality lesson plans with respect to the eight features (See Appendix A). Amy further revised this initial plan prior to her teaching of the landmark activity to produce an intended enactment that appeared to align closely to the original design principles of the Cornerstone Maths curriculum, particularly with respect to exploiting the dynamic features of the software to highlight the mathematical objective of the landmark activity, 
a clear indication of her personal orientation to embrace the DMT within her classroom practice.

Amy's real enactment deviated from her initial plan in the following ways:

- She initially adhered to her own lesson script, asking her planned questions verbatim, although on all occasions, she extended her questioning to encourage more complete explanations and to invite other students to enhance their peers' responses (Pedagogical Knowledge, Feature 1).

- In response to students' paired activity using the CM DMT, which generated discussions and written responses, Amy initiated several phases of whole class teaching that had not featured in her plan. These extra phases focused on aspects of mathematical notation, mathematical vocabulary and mathematical convention (Mathematical Content Knowledge, Features 4 \& 6; Technology instrumental genesis, Features 5 \& 7).

- Most significantly, although she had planned to 'play the simulation a few times', Amy did not actually initiate any planned whole class teaching where she used the DMT herself to highlight any of the mathematical ideas that the students were encountering. Her boardwork took the form of conventional note-taking. Furthermore, one unanticipated incident (a depleted laptop battery) prompted Amy to instruct a pair of students to work on the classroom interactive whiteboard. This public setting caught the attention of Amy (and other students in the class) as the boys struggled to decide if their edited simulation was faster or slower than the original (they had reduced the journey time). She took the interactive whiteboard pen from the boys and edited the graph, reiterating that, if the graph is less steep, the character would move more slowly. She did not play the animation nor refer to any of the other representations as a means to draw students' attention to why this was the case. In her post-lesson interview, Amy began by saying "We got a bit sidetracked, I was really surprised that they didn't know the units [for speed]" and added "I'm really disappointed with how that went", possibly indicating tensions between Amy's conceptualisation of the curriculum (on paper) and the enacted lesson. When prompted to expand, Amy expressed concern that the lesson was unlike their normal lessons as she had convened far more phases of whole class teaching (involving seven phases rather than the three she had planned). She reflected on the students' responses to the DMT tasks, heavily focused on how they had recorded their work on paper, for example 
how they had recorded their equations (the DMT displayed the gradient and intercept to one decimal place, whereas three students working in a group had each recorded this differently).

She concluded, after closer scrutiny of the students' written work, that they were "definitely beginning to realise the importance of all the things [representations] but they still don't know any of it".

\section{Discussion}

The macro-view provided by the analysis of the 42 lesson plans provided an insight into the range of the quality of lesson plans produced for the linear functions landmark activity and with this, an insight into teachers' underlying MPTK. Amy's case, which had scored highly with respect to its quality features, was selected as a significant one as her real enactment might provide validation of this insight and, more importantly highlight the gap between her planned and real enactment.

Amy exhibited confident pedagogical knowledge and mathematical content knowledge as her real enactment privileged these domains through thoughtful and sustained questioning involving several students and close attention to establishing correct mathematical norms that were appropriate to the age and ability of her students. Amy's personal orientation towards the use of the CM curriculum DMT was positive. She was aware of how it was acting as a 'window' on her students' mathematical understanding (Noss \& Hoyles, 1996), whilst at the same time was being challenged to rethink her mathematical and pedagogical goals.

Amy's instrumental genesis was at an early stage. Despite her personal confidence with the DMT she was still developing her repertoire in the classroom. Had it not been for the unplanned pupil use of the classroom interactive whiteboard, it is not clear whether she would have used the DMT 'live' with her students, as outlined in her lesson plan. However, this incident did impact on her understanding of her students' instrumental genesis as she observed them interacting with the DMT in a way that she had not foreseen. This example of a lesson "hiccup", a perturbation experienced by a teacher, triggered by the use of a DMT that prompts the development of MPTK (Clark-Wilson, 2010), highlights the crucial role played by classroom practice in such development. 


\section{Conclusion}

This study set out to explore how teachers' planned enactments for lessons involving DMT played out in the reality of their classrooms, providing insights into what and how they learned through this process. Whilst the analysis of the lesson plans suggested relatively low take-up of a key design principle of the CM curriculum - the use of dynamic multiple representations to highlight important mathematical relationships for linear functions - even fewer teachers were able to realise this feature in the classroom. We hypothesise that the gap between teachers' intended and real enactment is highly influenced by the teacher's confidence to enact the part of their plan that requires them to interact with the DMT at the front of the class, an aspect revealed by Amy's case. The notion of confidence (an aspect of Personal orientations) is an established factor in mathematics teachers' take-up of DMT and this research seems to corroborate other findings (Thomas \& Palmer, 2014).

Alongside, the critical aspect of a teacher's knowledge, 'contingency', which enables the teacher to respond to aspects of the lesson for which they had not (or could not) plan seems heightened in technology-enhanced mathematics instruction. This leads to the question, how does this knowledge emerge? In Amy's case, when reflecting on her use of the DMT during the lesson, she concluded that she would consider planning for a couple of students to use the interactive whiteboard as a pedagogic strategy since her class seemed highly motivated to see their peers' work. In addition, the incident had given her greater insight into the initial struggle that students experienced when learning to edit the graph (reflecting on her own experience during the initial PD session). This highlights the important role of lesson hiccups in technology-enhanced mathematics instruction - without these, how do we continue to expand our teaching repertoire such that we can take account of, and build on, the multiplicity of mathematically productive ways that we and our students can engage with DMT?

Our study highlights how and why, in the context of technology-enhanced mathematics instruction, the process of developing classroom practice (through multiple cycles of planning and reflection) is a crucial one. It is not sufficient to learn to use DMTs away from the classroom (on courses and teacher development programmes), without broader collaborative support in the school setting, which may explain why such technologies are still widely reported to be underused. Indeed, at the heart of such 
collaborative work should be the identification and exploitation of the lesson planning and enactment 'gaps' towards which we anticipate our methodological approach and theoretical framing can provide a contribution.

Furthermore, Amy's case adds a further distinction to Stenhouse's notion of the intended from the real curriculum (Stenhouse 1975). In his view, both a written plan and the vision a teacher has in mind are examples of the "intended" and enactment in the classroom is considered "real," pointing out that these are often not the same. Amy's case suggests that the written plan and the vision the teacher has in mind (both "intended") were also not always the same, which highlights how a written plan cannot (or possibly should not) capture a teacher's intended enactment.

\section{Ethical considerations}

The ethical approval of the project was granted by the UCL Institute of Education Ethics Committee (REC 692). The project adhered to the guidelines of the British Educational Research Association with respect to participants' voluntary informed consent, openness and disclosure, right to withdrawal and data privacy (British Educational Research Association, 2011).

\section{Acknowledgments}

The development of Cornerstone Maths (2010-13) was funded initially by the Li Ka Shing Foundation and it was an intensive collaboration between teams at the UCL Knowledge Lab, UCL Institute of Education, UK and at the Center for Technology in Learning, SRI International, Menlo Park, USA.

The research reported is part of a project, the Dynamic Technologies for Dynamic Mathematics Project, DTDM funded by the Nuffield Foundation (Award reference 9190). The views expressed are those of the authors and not necessarily those of the Foundation.

\section{References}

Aldon, G. (2011). Interactions didactiques dans la classe de mathématiques en environnement numérique : construction et mise à l'épreuve d'un cadre d'analyse exploitant la notion d'incident, Thèse de doctorat, , . (PhD), Université Lyon 1, Lyon. Retrieved from http://tel.archives-ouvertes.fr/tel-00679121 
Artigue, M. (1998). Teacher training as a key issue for the integration of computer technologies. In D. Tinsley \& D. Johnson (Eds.), Vol. 119, Proceedings of the IFIP TC3/WG3.1 Working Conference on Secondary School Mathematics in the World of Communication Technology: Learning, Teaching, and the Curriculum: Information and Communications Technologies in School Mathematics (pp. 121-129). London Chapman and Hall.

Ball, D. L., Hill, H. C., \& Bass, H. (2005). Knowing Mathematics for Teaching: Who Knows Mathematics Well Enough To Teach Third Grade, and How Can We Decide? American Educator(Fall 2005), 14-46.

Bretscher, N. (2014). Exploring the Quantitative and Qualitative Gap Between Expectation and Implementation: A Survey of English Mathematics Teachers' Uses of ICT. In A. Clark-Wilson, O. Robutti, \& N. Sinclair (Eds.), The Mathematics Teacher in the Digital Era: An International Perspective on Technology Focused Professional Development (Vol. 2, pp. 43-70). Dordrecht: Springer.

British Educational Research Association. (2011). Ethical guidelines for educational research. London, UK: British Educational Research Association.

Choppin, J. (2011). Learned adaptations: Teachers' understanding and use of curriculum resources. Journal of Mathematics Teacher Education, 14(5), 331-353. doi:10.1007/s10857-011-9170-3

Churchhouse, R. F., Cornu, B., Howson, A. G., Kahane, J.-P., van Lint, J. H., Pluvinage, F., ... Yamaguti, M. (1986). The Influence of Computers and Informatics on Mathematics and its Teaching (Vol. ICMI Study 1). Cambridge: Cambridge University Press.

Clark-Wilson, A. (2010). How does a multi-representational mathematical ICT tool mediate teachers' mathematical and pedagogical knowledge concerning variance and invariance? Institute of Education, PhD thesis. Retrieved from http://eprints.ioe.ac.uk/19941/ website:

Clark-Wilson, A., \& Hoyles, C. (2017a). Dynamic technology for dynamic maths [Final Report]. London: UCL Institute of Education.

Clark-Wilson, A., \& Hoyles, C. (2017b). Planning to teach lower secondary mathematics with dynamic mathematical technology: Quality features of lesson plans. Paper presented at the 13th International Conference on Technology in Mathematics Teaching, France. https://hal.archives-ouvertes.fr/hal-01632970

Clark-Wilson, A., \& Hoyles, C. (In press). A research-informed web-based professional development toolkit to support technology-enhanced mathematics teaching at scale. Educational Studies in Mathematics.

Clark-Wilson, A., Robutti, O., \& Sinclair, N. (Eds.). (2014). The Mathematics Teacher in the Digital Era: An International Perspective on Technology Focused Professional Development (Vol. 2). Dordrecht: Springer.

Department of Education. (2013). National Curriculum in England. Mathematics programmes of study: key stage 3. London: Department of Education.

Foster, C., Swan, M., \& Wake, G. (2014). The Lesson Study Process: Lessons for Mathematical Problem Solving. Nottingham: University of Nottingham.

Guin, D., \& Trouche, L. (1999). The complex process of converting tools into mathematical instruments: The case of calculators. International Journal of Computers for Mathematical Learning, 3(3), pp. 195-227.

Hoyles, C., \& Lagrange, J. B. (Eds.). (2009). Mathematics Education and Technology Rethinking the Terrain: The 17th ICMI Study. Berlin: Springer. 
Hoyles, C., Noss, R., Vahey, P., \& Roschelle, J. (2013). Cornerstone Mathematics: Designing digital technology for teacher adaptation and scaling. ZDM Mathematics Education, 45(7), 1057-1070. doi:10.1007/s11858-013-0540-4

Kaput, J. (1992). Technology and mathematics education. In D. Grouws (Ed.), Handbook of research on mathematics teaching and learning (pp. 515 - 556). New York: Macmillan.

Noss, R., \& Hoyles, C. (1996). Windows on mathematical meanings: Learning cultures and computers. Dordrecht: Kluwer Academic.

Office for Standards in Education. (2012). Mathematics: Made to measure. Retrieved from London:

Ruthven, K. (2014). Frameworks for Analysing the Expertise That Underpins Successful Integration of Digital Technologies into Everyday Teaching Practice. In A. ClarkWilson, O. Robutti, \& N. Sinclair (Eds.), The Mathematics Teacher in the Digital Era: An International Perspective on Technology Focused Professional Development (pp. 373-394). Dordrecht: Springer.

Schoenfeld, A. (2011). How we think. A theory of goal-oriented decision making and its educational applications. New York: Routledge.

Shulman, L. (1987). Knowledge and teaching: Foundations of the new reform. Harvard Educational Review, 56(1), 1-22.

Stenhouse, L. (1975). Defining the Curriculum Problem. Cambridge Journal of Education, 5(2), 104-108. doi:10.1080/0305764750050206

Thomas, M. O. J., \& Hong, Y. Y. (2013). Teacher integration of technology into mathematics learning. International Journal for Technology in Mathematics Education, 20(2), 69-84.

Thomas, M. O. J., \& Palmer, J. (2014). Teaching with digital technology: Obstacles and opportunities. In A. Clark-Wilson, O. Robutti, \& N. Sinclair (Eds.), The Mathematics Teacher in the Digital Era: An International Perspective on Technology Focused Professional Development (pp. 71-89). Dordrecht: Springer. 


\section{Appendix A Amy's lesson plan for the landmark activity}

Class: Year 8

Ability level: Top set

Before the lesson (your preparation): Have all resources printed. All laptops charged.

Students' prior experience/skills with the software: They may or may not have completed the Algebraic expression unit. All students will have completed activities 1, 2 and 3 in advance of this lesson so should be relatively comfortable with the software.

Key learning outcomes for your students: Students should be able to*

Describe how you will lead you class through Investigation 4 in phases:

\begin{tabular}{|c|c|c|}
\hline Phase & $\begin{array}{l}\text { What you will do... } \\
\text { How you will lead.... }\end{array}$ & Anticipated students responses/outcomes \\
\hline 1 & $\begin{array}{l}\text { All students to log in to laptops. The main } \\
\text { whiteboard will show the same screen that } \\
\text { they will open up - Activity } 4.1 \text {. All students } \\
\text { to have their workbooks ready and opened } \\
\text { at page } 13 . \\
\text { A snapshot recording of their voices in the } \\
\text { previous lesson will be ready as a reminder } \\
\text { of what they achieved in the previous } \\
\text { lesson. A question relating to this recording } \\
\text { will be asked. }\end{array}$ & $\begin{array}{l}\text { All students to have highlighter ready and } \\
\text { highlight key words as they read } 4 \text { paragraphs in } \\
\text { two minutes. Students to read paragraphs. } \\
\text { Timer ready for two minutes. Students will be } \\
\text { asked to highlight the key sentence across all } 4 \\
\text { paragraphs which encourages detailed reading. }\end{array}$ \\
\hline 2 & $\begin{array}{l}\text { Simulation played initially on board. } \\
\text { Students play simulation on their own } \\
\text { screens and independently give answers in } \\
\text { their books on page } 13 . \\
\text { Students directed to get Shakey to move } \\
\text { more slowly. Will they be able to edit the } \\
\text { equation (unlikely) or move the graph so } \\
\text { that it has a lower gradient to make Shakey } \\
\text { go more slowly? } \\
\text { Will I use the word gradient - a numerical } \\
\text { value, or will they use the word steepness - } \\
\text { a qualifier? }\end{array}$ & $\begin{array}{l}\text { Students to write their new graph equations in } \\
\text { their books. "What do you notice?" There is no } \\
\text { need to say whether they are right or wrong at this } \\
\text { moment but circulate to see what each group is } \\
\text { saying. } \\
\text { Will the students copy down the equation as it is } \\
\text { written on their screen or will they simplify it to } y= \\
4 x \text { instead of } y=4.0 x+0 ? \\
\text { Students write down what they notice in the two } \\
\text { separate graphs. Coefficient - will teacher ask } \\
\text { students "Can you re-write your sentence below } \\
\text { but this time include the word coefficient?" }\end{array}$ \\
\hline
\end{tabular}




\begin{tabular}{|c|c|c|}
\hline 3 & $\begin{array}{l}\text { Page } 15 \text { is shown on the IWB to help direct } \\
\text { students. They fill in the table using } \\
\text { instructions given in the book. } \\
\text { The whole page will be filled before a whole } \\
\text { class discussion takes place. } \\
\text { Whole class discussion will be based on } \\
\text { individual students' answers collected on } \\
\text { post-it notes and read out. Students to go } \\
\text { to the board and point to the areas which } \\
\text { they are discussing. Focus on gesturing } \\
\text { and pointing to key areas of discussion. } \\
\text { Play the simulation a few times. } \\
\text { The discussion may include the following } \\
\text { questions: "What does x represent in the } \\
\text { equation? What does the steepness of the } \\
\text { graph represent?" }\end{array}$ & $\begin{array}{l}\text { Variable is the keyword here. If students identify } \\
\text { that x represents time and that time changes, that } \\
\text { would be an excellent outcome but if students } \\
\text { don't yet know, they do not need to be corrected. } \\
\text { If students don't know what to write here, } \\
\text { encourage them to explicitly write "I don't know". } \\
\text { In part B, the word output might be encouraged as } \\
\text { a link to distance. } \\
\text { In part C, it is acceptable for a student to write that } \\
\text { steepness represents the speed of the robot but } \\
\text { they do not need to think about calculating } \\
\text { gradients at this point. }\end{array}$ \\
\hline
\end{tabular}

Things not to forget: All laptops charged. Questioning is more important than correct answers.

Any planned additional resources (yours): Homework - mini murder mystery hunt on linear functions.

*Amy did not complete this section. However, when prompted during the post-lesson interview, she responded "I wanted them to be able to identify that - in terms of the equation - that the number in front of $\mathrm{x}$ was the gradient or that it related to the steepness or how fast Shakey was moving and that, potentially, what all the representations were". 
Appendix B Visual map of lesson observation of landmark activity, with a zoomed in section. 


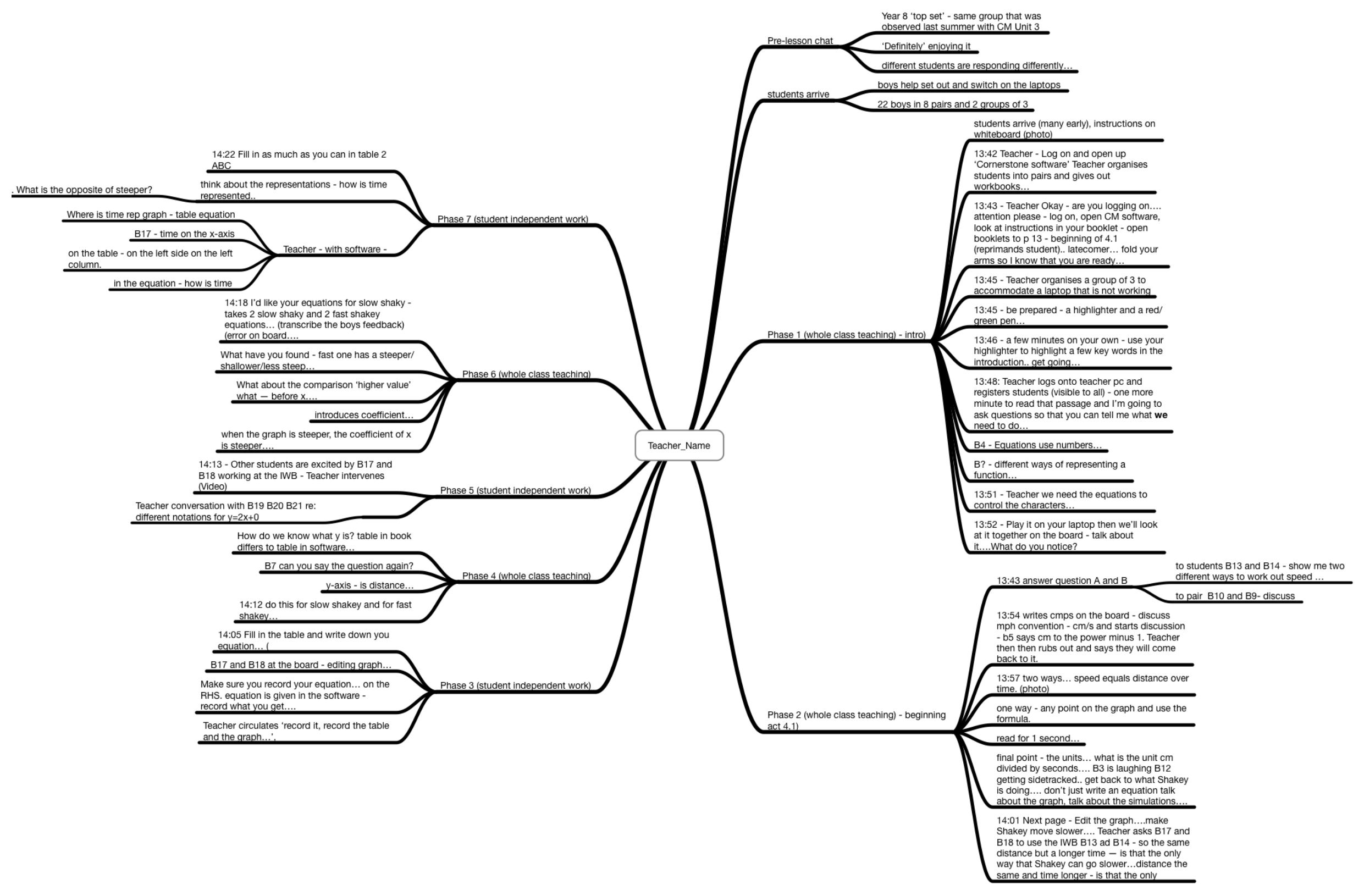




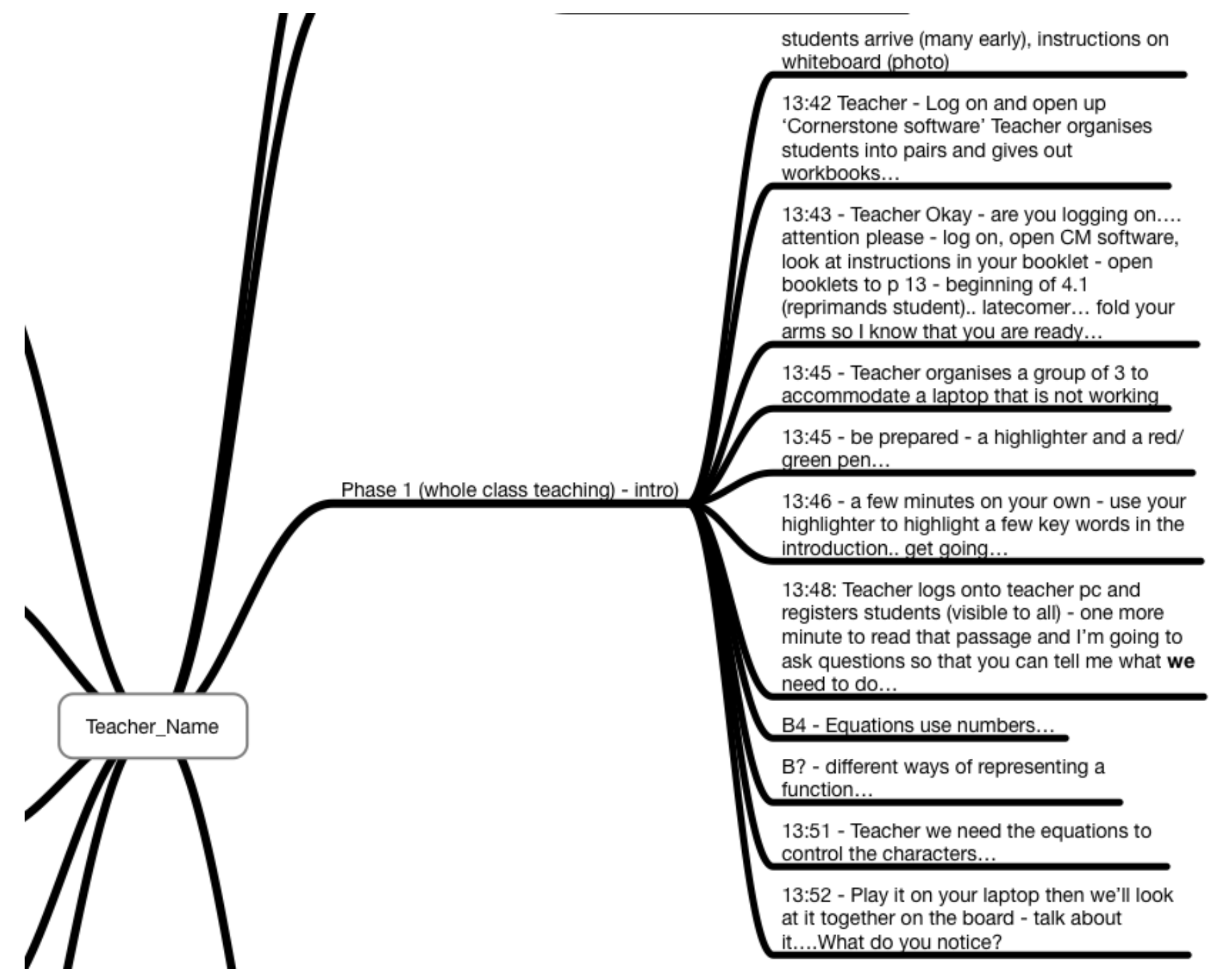

